\title{
Indoctrination Power of Network Media
}

\author{
Bin Liu \\ Mangement departmentine \\ Jiangsu Police Institute \\ Nanjing, China \\ Duke University Political science department \\ Durham, American \\ Liubin000@163.com
}

\begin{abstract}
Network media is the most important transmitting vector in today's information society. People acquaint the realistic society increasingly from the network world. However, there is still certain deviation between the "subjective reality" and the objective one. In this paper, the network public sentiment dissemination model describes that the network public sentiment has such an indoctrination power which restricts secretly the people's view of reality in the process of unconsciously influenced and long-term cultivation. Therefore, how to play the indoctrination power of network media and give play to its positive effect needs to be guided in several aspects, such as agenda setting, cultivation analysis, and news frame and media literacy.
\end{abstract}

Keywords-Cultivation Analysis; Network Public Sentiment Dissemination Model; News Frame

\section{INTRODUCTION}

The founder of Communications Paul Lazarsfeld and Morton believe that mass communication will make modern people satisfied with in superficial information and have the negative function of nerve anesthesia. It is undeniable that the network plays an increasingly important role in modern life with its unique charm in today's information society. We usually know the realistic society from the network which does not preach but convey information to the audience in forms of "offering entertainment" and "reporting the facts". It secretly exerts a subtle influence on people's view of reality. However, this view is also different from the real objective reality and the difference is rather obvious. We know that if a society, as a unified entirety, wants to exist and develop, social members need to have a "consensus" on the society, namely having a roughly consistent or similar cognition of the objectively existing things, important affairs and all kinds of social affairs, various parts and their relations. Only on this basis, people's cognition, judgment and behaviors can have a common benchmark and social life can achieve the coordination. Providing this "consensus" is an important task of social communication. It is borne by the education and religion in the traditional society, but it is completed through the mass communication in the modern society. Today, the network has played a leading role, because the network's influence on the audience has incomparable advantages compared to other communications media. ${ }^{[1]}$

Fund Projects: College Philosophy and Social Science Fund Program of the Education Department in Jiangsu Province 2014SJB239; Scientific Research Project of Jiangsu Police Institute 2014SJYSY17; General Project of Humanities and Social Sciences Research of Ministry of Education 11YJA630060; Funding Project of Leading Discipline Construction Engineering of Universities in Jiangsu Province, Funded by Provincial "Qing-lan Project” "333 Program".
A Plenty of audiences: Network has multitudinous audiences. Up to December 2013 Internet users in China had reached 618 million. b. Long time: In 2013, the time of China's Internet users per capita was 25.0 hours per week online, increasing by 4.5 hours over last year. In recent years, China's netizens have spent increasing hours in surfing the Internet. The rapid development of Wi-Fi, 3G and today's 4G network has better satisfied netizens' use demands for all kinds of applications and made netizens gradually shift from relatively simple applications, such as fragmented reading and news, to social contact, life service applications with longer hours and bigger adhesiveness, which has improved the overall use time on the Internet in applications' use breadth and depth. c. Close contact: Modern people have been bundled together with network from an early age. It is difficult for them to distinguish the real world from the "virtual world". Netizens under the age of 10 have accounted for $1.9 \%$ of the total with an increase over the previous year. d. Wide coverage: Network has widely permeated all levels of society. Seen from the degree structure, occupational structure and income structure, people in every degree, occupation and income class are inseparable from network. e. Profound influence: Network has strong sense of presence, witness and impact. Especially network games make a lot of netizens unable to pull away from them. All these characteristics of network make it have greater power than any other media in history. ${ }^{[2][3]}$

\section{Network Public SEntiment Dissemination Model}

In today's social life, most relations between individuals, the outside world and themselves depend on network communications as media. The information we have received from the network substantially exceeds that directly derived from the interpersonal communication. For people in modern society, especially those in the metropolis, their ways of life, thinking patterns and values are mostly and heavily influenced by the network. The greatest value of the network is not only reflected in its vast amounts of information and real-time transmission, but also more in its interactivity. The interactivity of the network public sentiment id mainly embodied in interactions between netizens, the government and network media and the interactions between Internet users. The key to the quality of public sentiment lies in its rationality. ${ }^{[4]}$

Network public sentiment dissemination model (see Chart 1) shows the process of network information dissemination. It refers to the process that information publishers input text information, videos, games or other contents through the carrier Internet and then Internet users choose and process topics they are interested in through discussion, follow-up comments and other forms. Then, they 
output waves of public opinion, showing different information environments. However, people's perception of the information environment, namely the environmental cognition, actually deviates from the objective conditions in reality. Analyzing the quality of the network public sentiment is actually to analyze the interest appeals of main participants in the network public sentiment and the results they pursue. ${ }^{[5]}$

Network public sentiment dissemination model Chart 1 (Network Public Sentiment Dissemination Model) ${ }^{[6]}$

: SIPOR represents source, inputs, process, outputs and information receaver.

Source: information publisher

Inputs: text information, videos, games

Process: discussion, follow-up comments

Outputs: waves of public opinion

Information receaver: information receiver

\section{ANAlysis OF The CUltivation OF Network Media}

The Japanese scholar Shimizu Ikutaro holds the view that the modern society is a society dominated by massive duplications of information. And the network, with its powerful spread of the mass information, has made broad audiences drowned in the "flood" of superficial information and made them lose abilities of rational thinking and judgment of things. Network transmission, for the modern people, is similar to a kind of "psychological violence". Modern people are absorbed in their cell phones regardless of occasions and time, on the bus, subway and at the dinner table. The sensation and irritation that the network has brought to people has made people degenerate to the situation of "watching cell phones while sucking fingers" just as American psychiatrist has said.

In fact, the contents that the network has spread possess specific values and ideological tendencies. In order to "catch people's eyes", some network media irresponsibly propagate vigorously and launch distorted reports, which can mislead the audience mightily. Currently, bloody violence scenes in network games, films and television works have fostered people's ruthlessness and inhumanity to a great extent. People's temperaments and behaviors are infected by violence and some people have committed crimes and taken the deadend path. ${ }^{[7]}$

The publicizing and reporting of the extremely violent events in the network have also played an important role in inducing the occurrence of such events to some degree. Obsessive media attention has resulted in frequent occurrence of events and the network's amplification effect has played a demonstration effect for some behavior. For instance, there were several events of chopping people outrageously on campus that continually occurred in 2010. On March 23, 2010, a vicious homicide happened in front of the gate of Experimental Primary School in Nanping, Fujian Province. The perpetrator was a dismissed community doctor who killed viciously within one minute with the psychology of taking revenge on society. Eight students in Experimental Primary
School in Nanping, Fujian Province were killed and five were wounded. On April 12, 2010, a tragedy took place in Hepu County, Beihai City, Guangxi Province. A psychopath chopped toward passersby and seven people were killed and injured in the accident. On April 28, 2010, a retired teacher due to illness wounded 18 students and a teacher in Leizhou, Guangdong Province. On April 29, 2010, the attack happened in Center Kindergarten in Taixing, Jiangsu Province and 32 people were injured, including 29 children, 2 teachers, 1 security guard. Among them, eight children were badly hurt. On April 30, 2010, a villager in Shangzhuang Village, Weifang City, Shandong Province, and Wang Yongqiang broke into Shangzhuang Elementary School, injured five preschool students with a hammer and set fire to two students with gasoline. There are many reasons for intensive outbreaks of such events, but we have to say that there is a certain correlation with the excessively exaggerated reports of facts on the Internet, which have contributed to the frequent outbreaks of such events to some extent. In addition, the network violent games also have a deep influence on people's behaviors. The survey results concluded by Lv Na showed that teenagers who committed crimes due to the influence of violent video games accounted for $29.6 \%$. $^{[8]}$

\section{The Guidance of Network Public SENTIMENT}

\section{A. The function of agenda-setting and theory of cultivation} analysis are effective methods of leading the network public sentiment.

Network media can convey specific values and ideological tendencies to the audiences and make people form the views of society and reality by offering entertainment and reports of facts in silent transforming influence. However, these effects are cumulative and take place imperceptibly in a long-term process. Therefore, in the network public sentiment transmission, network media should be aware of their own leavening cultivation effects and realize their functions by reporting the facts, providing entertainment and other ways. American communication experts McCombs and Shaw proposed "the mass media has a function of agenda-setting for the public, news reports information activities of media affect people's judgments of 'events' and their importance in the world around by endowing all kinds of 'issues' with different levels of significance". In other words, the mass media are not only the main information sources but also important impact sources, striving to find good topics and make them promoted to the public agenda. This requires the media have the keen insights, can make full use of news events and incidents, grasp opportunities to report and comprehensively utilize various mass media to popularize literacy and guide public opinions. That is the network media can choose some positive issues to report and propaganda in the input stage. Especially the opinion leaders should play a more dominant role in public sentiment. The network media should grasp the direction, be responsible, carry forward social justice and spread the mainstream culture in publicity and reports. Especially in large and hot issues, they should instruct actively, correctly and effectively and appropriately guide the masses' views of issues, which are responsibilities that network media should undertake. ${ }^{[9]}$ 


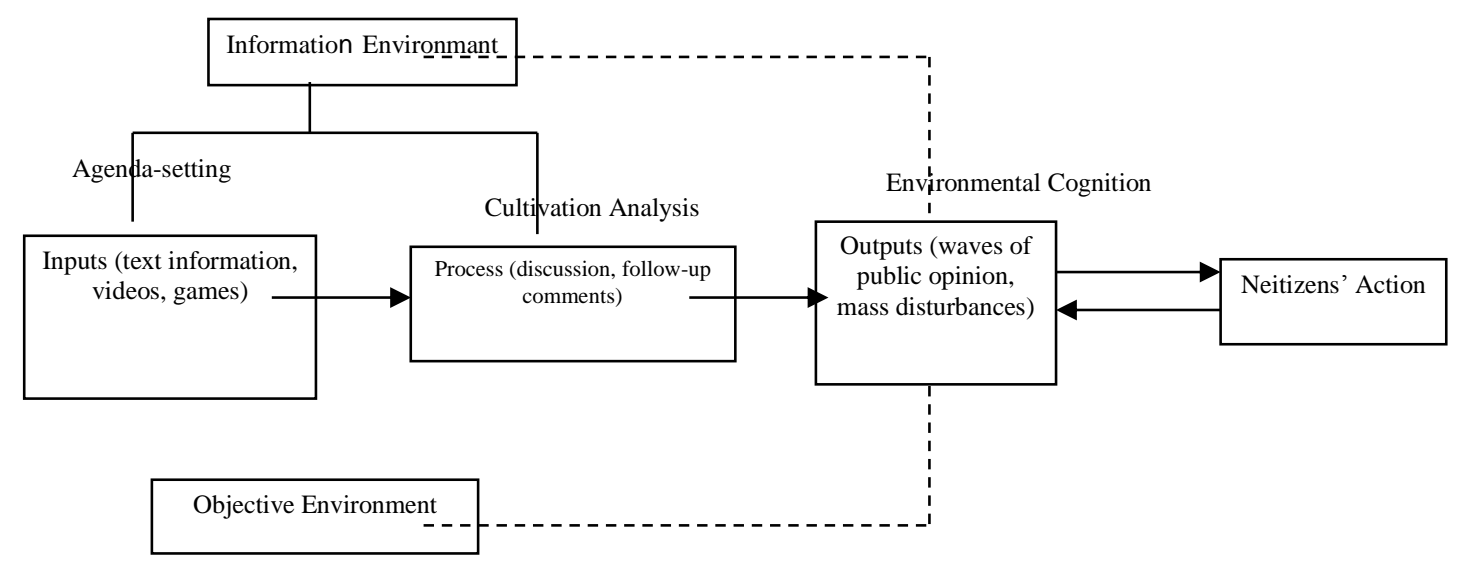

Fig. 1. Network Public Sentiment Dissemination Model

\section{B. News frame should be the way to reconstruct the news.}

The concept of frame originated from sociology and entered the field of mass communication research after being introduced by Canadian sociologist Goffman. American researcher of News Frame Theory Entenmann thought, "Frame includes two functions, selecting and highlighting. Framing one thing means selecting the needed sections and specially processing in the report to reflect significance explanation, attribution inference, moral evaluation and treatment recommendations". News frame has an important influence for audience to know and understand the news events and respond to them. In order to attract the public's attention, a lot of media do not scruple to make a lot of lurid headlines, words and garble a deliberate misinterpretation out of context. For instance, on May 28, a woman was beaten to death in KFC in Zhaoyuan City, Shandong Province. It was known nationwide that heretics killed the women. However, the initial report of this case titled "A Woman Refused to Chat, Beaten to Death by Six People". Obviously, this headline was completely inconsistent with the content. Quite a lot of such reports have made the distortion and misunderstanding caused by the leading frames of media result in frequently severe social influence and mass disturbances.

\section{Media literacy is the crux of the network media interaction}

Qualified "general public" should be cultivated for the information society, including their independent abilities to distinguish, select and evaluate the media and the information contents. The ability of democratic participation should be actively promoted in communication process through abilities to rationally dialogue, supervise and affect media and by spreading to create. Especially the big Vs on the Internet should serve as opinion leaders and play a positive role in the dissemination of network public sentiment. Netizens should keep rational in the process of participation and should not loosen their tongues without scruple due to "Spiral of Silence". Admittedly, legal regulations are rather important in network management. Equally, moral constraints are also absolutely necessary. ${ }^{[10]}$

\section{REFERENCES}

[1] Guo Qingguang, Journalism \& Communication. Beijing: China Renmin University Press, 2012.

[2] Lv Na, A Study of Network and Psychology of Juvenile Delinquency, Hebei Law Science, 2008 (04).

[3] The 33rd Statistical Report on Internet Development in China [EB/OL]. http://www.cnnic.net.cn/hlwfzyj/hlwxzbg/hlwtjbg/201403/P0201403053 46585959798.pdf,2014-03-05/2014-05-30

[4] Chen Yuesheng, Perspective of Public Opinion of Components, Characteristics and Types of Unexpected Mass Incidents, Theory Monthly, 2006 (02).

[5] Jiang Lejin, Formation and Function of Network Public Opinion, Journal of Beijing Institute of Technology (Social Sciences Edition), 2006 (04).

[6] Liao Weimin, Transmission Characteristics of Network Public Opinion in Public Emergencies, Press Outpost, 2010 (11).

[7] Zhang Jing, A Study of Network Transmission of Rumors, China

[8] Newspaper Industry, 2012 (22).

[9] Shan Gang, A Study of Socialist Core Value System Leading Diverse Social Ideological Trend: A Discussion from the Perspective of Communication, Press Circles, 2011 (02).

[10] In Jianbin, The Evolution Mechanism of Network Public Opinion, Media, 2008 (04)

[11] Nong Yu, Application of Communication Theory in the Information Dissemination of Intangible Cultural Heritage: A Case Study of Tianjin, China Newspaper Industry, 2013 (07). 